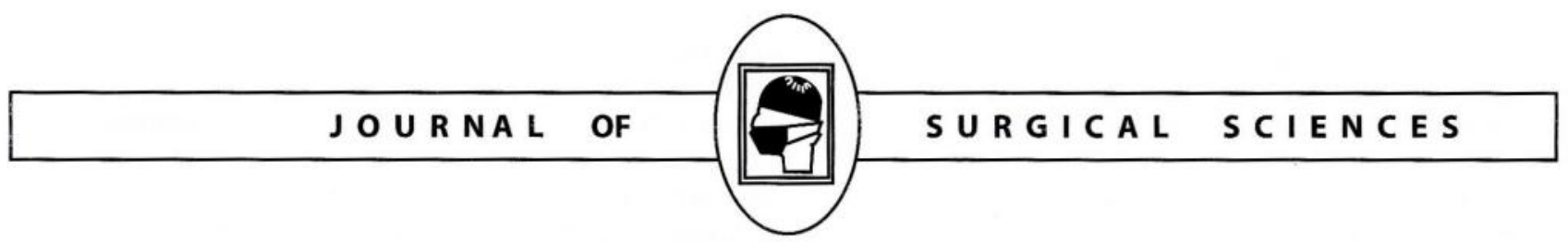

\title{
Editorial
}

\section{Surgical education and training: moving towards twenty first century}

Dr. Md. Margub Hussain

Professor of Surgery, Popular Medical College, Dhaka

Surgery is progressing, embracing changes and keeping in pace with expansion of medical science and technological development. New knowledge, technology and procedures are being incorporated ever increasingly for diagnostic and therapeutic purposes into the care of surgical patients ${ }^{1}$. The goal of medical care now embraces universal health care. Sustainable Development Goal (SDG) called for 'safe surgery and anesthesia at affordable cost whenever is needed'. To accomplish this global challenge we have to take strategies and steps so that next generation surgeons of our country can confidently work shoulder to shoulder in a team in any national or international perspective.

Though Galen, the great physician-surgeon of Roman Empire (AD 131-201) is believed to begin teaching surgery, it was not until $1300 \mathrm{AD}$, when surgery was beginning to be taught formally as part of medicine in a university setting. Before that surgical knowledge and techniques were communicated by individual practitioners privately ${ }^{2}$. Surgery continued to be taught in Italian schools in the fourteenth and fifteenth centuries, though it was at a much lower status than medicine.

Surgical training also started in Italy and then extended to other European countries. Most senior surgical college, the Royal College of Surgeons of Edinburgh, was formally incorporated in 1505 . This charter imposed that every master surgeon should have full knowledge of anatomy and surgical procedures; that all apprentices be literate; and that this knowledge be thoroughly tested at the apprenticeship end. Halsted started surgical apprenticeship at Johns Hopkins Hospital and school of Medicine in 1889. His aim was to train young surgeons not only as competent operating surgeons, but also as able surgical teachers ${ }^{3}$. Teachers and professionals of contemporary surgery cherish the same goals and principles.
Proficiency of a surgeon, especially in Postgraduate level, has been extended and redefined to incorporate newer competencies. These include, besides clinical and surgical skills, a broad range of technical, interpersonal, administrative, and research abilities. Academic leadership and professionalism is also given high value in training of a surgeon. Patient safety and privacy is now given paramount importance in the care of surgical patients.

In apprenticeship model of surgical training that has been in practice, high volume of patient exposure were considered as principal mode of learning by surgical trainees. This self learning method as in adult learning theory required much time and motivation on part of trainees. Guidance by supervisors were to a variable extent subjective. Opportunities for learning through work with "real" patients though had definite positive impact on the trainees, sometimes novices were found not adequately prepared rendering learning piecemeal. Moreover, involvement of supervisors and trainers in various administrative responsibilities limited interactions among trainees and trainers. Evaluation of competence relied heavily on exit or summative examinations that were rigorous though not at specified standard across the examining bodies.

Now, in postgraduate medical education, there is a conceptual shift towards graded competency based highly sophisticated and structured teaching learning programs. The components of these programs are planned clinical or practical placements with expert supervision, theoretical teaching, research experience, systematic assessments and evaluation of the education programs. Training programs have been designed to ensure accomplishment of all compe -tencies and contents of curriculum intended to enable an aspirant trainee doctor to a consultant 
surgeon and according to future needs in professional life. Fitts and Posner's three-stage theory of motor skill acquisition is widely accepted in skills development of the surgical trainees. According to this theory, in the cognitive stage, the learner intellectualizes the task; during integrative stage knowledge is translated into appropriate motor behavior.In the autonomous stage, practice gradually results in smooth performance. The earlier stages of teaching technical skills may take place outside the operating room, in the surgical skills laboratory. Practice is the key for automaticity in basic skills and trainees are encouraged to do deliberate practice. This mastery of basic skills allows trainees to focus on more complex issues, both technical and nontechnical, in the operating room.

21st century brings special context for surgical teachers and trainers. These include changing treatment patterns, increased diversity in trainees and much sicker and more complex problems in patient populations, restrictions on how we train our students, increased concerns about patient privacy, and an aging population. Specified work hours for residents, structuring of training programs, shrinkage in available operating-room time, and ethical imperatives to protect patients from harmare newer challanges ${ }^{4}$. Minimally invasive procedures are being used ever increasingly in various capacities. Tele surgical techniques are becoming reality. Imaging and IT has made it easy to take any image and transfer to places instantly to use for patient benefit and teaching learning purpose.

The expectation that trainees will acquire all necessary skills in a purely clinical environment is no longer realistic. Diminished opportunity and increased concern of patient safety has developed interest in developing laboratories with formal curriculum, specifically designed to teach surgical skills. In this new model of surgical education, basic surgical skills are learned and practiced on animal and inanimate models, cadavers and simulators, with the aim of better preparing trainees for the operating room experience. Simulation offers the benefits of a safe environment for practice and error, opportunities for feedback and assessment, and standardized experience for trainees ${ }^{5}$. Simulation transforms a novice into "pre-trained" novice, better prepared for clinical situations; this also ensures patient safety.

Acquisition of non-technical factors such as communication, leadership and teamwork have also been shown to play a substantial role in operative procedural success. These nontechnical factors have been shown to reduce the rate of errors in the operating room significantly. Simulators also have potential for use in teaching and assessment of non-technical skills.

In order to better plan instructions and assess the efficacy of curricular interventions, valid and reliable assessments of technical skills are needed. To ensure effectiveness of training, assessment is done at key points. Evaluation is made according to set standards set in the curriculum. These formative assessments are followed by feedback to individual trainees so that they can correct themselves. Training activities of each trainee is also documented and made official. Efforts have focused on techniques that standardize the assessment process outside the operating room. One such method is the Objective Structured Assessment of Technical Skills (OSATS) ${ }^{7}$. OSCE and OSPE has also been extensively used for objective evaluation and personalized feedback. In addition various methods of WBA(workplace based assessment) is extensively being used for post graduate trainees as formative assessment and feedback. Other methods of assessment include the McGill Inanimate System for Training and Evaluation of Laparoscopic Skills (MISTELS) and the Imperial College Surgical Assessment Device $(\text { ICSAD })^{8}$.

With the development of formal training programs, the development of published research works has become allied with successful training progression and more recently associated with assessment of competence progression.

In our perspective, leaders in surgery and concerned people need to revisit post-graduate surgical curriculum and training program so that surgical trainees may be engaged in a gradually increasing higher and complex responsibilities. Skills development centers with locally available and affordable inanimate and animal models may be arranged for early year trainees. Tremendous improvement and easy availability of imaging and image transfer allows using IT facilities in the training of surgical training. Trainees may be exposed to clinical materials, videos and live operative procedures from any, even distant internationally reputed centers. Institutions in our country may also develop exchange programs that might facilitate training. Trainers should engage their trainees in active learning and critical thinking.

Internationally, standards of post-graduate trainee has been defined by bodies like World Federation of Medical Education (WFME). 
A national standard must be agreed upon adapting to standards set by international bodies.Expert close observation of trainees during patient encounters and regular assessment of each of the trainees at every key point must be ensured and formalized. All assessments must be made according to the agreed national standard. Effective mentoring is especially appreciated in the training of surgeons.

Teaching and training during undergraduate education program should also be revised. A committed faculty member guided and supported by authorityshould be in charge of the program. In the clerkship, medical students should be engaged in active learning and problem solving process. Students also should be provided with maximum possible clinical resources during bedside teaching to ensure adequate exposure. Some operating room experience of common procedures are also needed. Graduate students during their surgery placement may be exposed to images, videos and live procedures in our set up and other sophisticated centers. Inanimate and virtual models may be used for teaching basic surgical skills in the skill rooms of each institutions. Avariety of evaluation and testing methods based on the learning objectives of the clerkship should be used $^{9}$.

Updating of surgical curriculum and a suitable training program and creating an enabling academic environment is a collective responsibility of government and non-government organizations, universities, post-graduate institutions and examining bodies. Implementation of the program needs commitment of all faculties. Professional bodies have to initiate the processand pull togetheracademics in surgery to design post-graduate teaching and training program that support the vision of surgical services. Creation of a critical mass of academics of surgical professionals is also need to be encouraged through this program to shape future of surgery. This is also imperative that all post-graduate trainings must be regulated by an independent body and trainings are made full-time residential with incentives.

\section{References}

1. Rutkow I, History of surgery in Townsand $C$ $M$, Beauchamp R D,Evans B M,Mattox K L, editors, Sabiston text book of surgery: The biological basis of modern surgical practice. 19th edition, Elseiver, Saunders. Philadelphia.2012.

2. Mc Vaugh $M$, Surgical education in the Middle Ages. Dynamis. 2000; 20: 283304.

3. Matthews $\mathrm{AH}, \mathrm{Abdel}$ rahman $\mathrm{T}$, Powell $\mathrm{A}$ G.M.T, and Lewis W G, Surgical Education's 100 Most Cited Articles: A Bibliometric Analysis .

4. Haluck RS, Krummel TM. Computers and virtual reality for surgical education in the 21st century. Arch Surg 2000;135:786792

5. Reznick R K and MacRae H. Teaching Surgical Skills - Changes in the WindN Engl J Med 2006; 355:2664-2669.

6. Martin JA, Regehr G, Reznick R et al. Objective Structured Assessment of Technical Skill (OSATS) for surgical residents. Br J Surg 1997;84:273-278

7. Fried GM, Feldman LS, Vassiliou MC, et al. Proving the value of simulation in laparoscopic surgery. Ann Surg 2004;240:518528

8. Taffinder N, Sutton C, Fishwick RJ, McManus IC, Darzi A. Validation of virtual reality to teach and assess psychomotor skills in laparoscopic surgery: results from randomised controlled studies using the MIST VR' laparoscopic simulator. Stud Health Technol Inform1998;50:124-130

9. Schwartz R W, Donnelly M B, Nash PP, Witte $\mathrm{F} \mathrm{M}$, and Griffen, Jr W O, Undergraduate surgical education for the twenty-first century.Ann Surg. 1992 Dec; 216(6): 639-647. 